\title{
Prevalence, trend and outcome of twin pregnancy in Rivers State University Teaching Hospital, Southern Nigeria
}

\author{
Felix Chikaike Clement Wekere ${ }^{1 *}$, Dickson H. John' ${ }^{1}$, \\ Gift A. F. Clement-Wekere' ${ }^{2}$, Rose S. Iwo-Amah ${ }^{1}$
}

\begin{abstract}
${ }^{1}$ Department of Obstetrics and Gynecology, Rivers State University Teaching Hospital, Rivers State, Nigeria
${ }^{2}$ Department of Paediatrics and Child Health, University of Port Harcourt, Rivers State, Nigeria
\end{abstract}

Received: 19 May 2021

Accepted: 05 June 2021

\section{*Correspondence: \\ Dr. Felix Chikaike Clement Wekere, \\ E-mail: fccwekere@yahoo.com}

Copyright: ( $)$ the author(s), publisher and licensee Medip Academy. This is an open-access article distributed under the terms of the Creative Commons Attribution Non-Commercial License, which permits unrestricted non-commercial use, distribution, and reproduction in any medium, provided the original work is properly cited.

\begin{abstract}
Background: Multiple pregnancy is a high-risk pregnancy associated with a higher maternal and perinatal complications compared to singleton pregnancy. Twinning is the commonest form of multiple pregnancy, and its prevalence varies across the globe, with lowest value in Japan and highest in Nigeria.

Methods: The aim of the study was to review twin births in Rivers State University Teaching Hospital (RSUTH), to determine its prevalence, trend, and management outcome.

Results: During the period under review, there were 13516, and 263 twin births, giving the prevalence of twinning in RSUTH as 19.5 per 1000 live births or 1 in 51 deliveries. The rate of twinning increased from 7.6 per 1000 deliveries in 2015 to 35.7 per 1000 deliveries in 2019. Mean age of patients was 31 SD 4.82 years, 95\% CI: 30.42, 31.59, and modal age group was 30-34 years. Patients' parity ranged from 0 to 7 with modal parity being para-1. Majority (51.7\%) had secondary level education, and were Christians. Preterm delivery rate was $62.4 \%$. The mean gestational age at delivery was 35.7 SD 2.9 weeks, 95\% CI: 35.3, 36.0. The mean birth weights of the first and second twins were 2.39 SD 0.67 and 2.30 SD 0.69 respectively. Majority (92\%) of the foetuses were alive at birth. Still birth and perinatal mortality rate were 4.2 and 7.8 per 1000 live births. There was no case of maternal mortality.

Conclusions: The rate of twining in our setting is high, with an increasing trend. Most of the parturient had preterm delivery, and improved perinatal care services would ensure best perinatal outcome.
\end{abstract}

Keywords: Twins, Multiple gestation, Prevalence, RSUTH, Nigeria

\section{INTRODUCTION}

In recent decades, the prevalence of multiple pregnancy has increased progressively perhaps due to advanced age at conception, and advent of assisted reproductive technology. ${ }^{1,2}$ Globally, multiple births accounts for about $3 \%$ of all deliveries. ${ }^{3}$ Multiple pregnancies consist of twin and higher order pregnancies (triplets, or more); with twins being the commonest type. ${ }^{4,5}$ It is a high-risk pregnancy associated with higher adverse maternal and perinatal outcomes compared to singleton pregnancy. ${ }^{2,6}$

Generally, black race has the highest rate of multiple gestation, followed by white race and lowest among the
Orientals. ${ }^{4}$ The incidence of twinning ranges from 4 per 1000 deliveries in Japan to about 54 per 1000 deliveries in Western Nigeria. ${ }^{2,7,8}$ In United States, the rate of twining increased by over $75 \%$ from 1980-2009. In Brazil, twins accounts for 2 to $4 \%$ of all births. ${ }^{8}$ Worldwide, Nigeria is known to have the highest rate of multiple pregnancies. ${ }^{4}$ In Nigeria, the highest incidence rate of twinning has been reported in South-West. ${ }^{9}$ While the rate of monozygotic twining is constant worldwide, dizygotic twin pregnancies account for the varying rates of multiple pregnancies. ${ }^{8}$

Multiple pregnancies result from fertilization of two or more oocytes by two sperms giving rise to dizygotic twins, or fertilization of a single oocyte with its subsequent 
splitting to generate similar structures that give rise to monozygotic twins. ${ }^{2,4}$

About one in five of all twins are monozygotic; splitting within the first 72 hours of fertilization, results in dichorionic diamniotic twins. However, division that occurs within 4-7 days and 8-12 days after fertilization leads to monochorionic diamniotic (MCDA) and monochorionic monoamniotic (MCMA) twins respectively. Division beyond 12 days is known to result in Siamese or conjoint twins. ${ }^{2,4}$

Although increased rate of spontaneous twining has been reported in Nigeria, studies have shown that the incidence of monozygous twining is increased by 8 -fold due to artificial reproductive technology (ART) ${ }^{2,10}$ Advanced maternal age has also been shown to be associated with increased spontaneous dizygous twining especially those in the age group 30-39 years. $^{2}$ Unlike monozygotic twining, the incidence of dizygotic twins is affected by advanced maternal age, artificial reproductive technology, race, environmental factors use of oral contraceptives, genetics, dietary factors, ovulation induction drugs, and maternal weight/large body mass index..$^{10,11}$

Multiple pregnancy has not been studied in our centre. With regards to advances in assisted reproductive technology, and increasing maternal age at first birth in our environment, report of spontaneous twining in Nigeria as well as high risk nature of multiple pregnancy, there is need to review twin birth in our setting.

The aim of the study was to review twin pregnancy in Rivers State University Teaching Hospital (RSUTH) over a 5-years period, to determine the prevalence, trend, mode of delivery and outcome of management.

\section{METHODS}

This cross-sectional study was carried out at the Rivers State University Teaching Hospital (RSUTH), Port Harcourt, Nigeria. RSUTH is one of the Teaching Hospitals in Rivers State, Nigeria. It is situated at the heart of the city and receives referrals from other health facilities within and outside the State.

Records of two hundred and sixty-three women with twin pregnancy from $1^{\text {st }}$ January 2015 to $31^{\text {st }}$ December 2019 were retrieved from the antenatal, labour ward and theatre registers, and reviewed.
Special data collection forms were used to collect data on the women's socio-demographic characteristics of patients (age, parity, educational status, religion, booking status), mode of delivery, birth weights, management outcomes of twin pregnancies (alive or dead).

Data were extracted, sorted, coded and analysed using IBM Statistical Product and Service Solution (SPSS), formerly known as Statistical Package for the Social Sciences, version 25.0 Armonk, NY. Categorical variables were summarized in frequencies and percentages while continuous variables were summarized using mean and standard deviations with $95 \%$ confidence intervals around the point estimates.

Results were presented in figures and tables as appropriate for the data. Ethical clearance for the study was obtained from Research Committee.

\section{RESULTS}

Over the period reviewed, there were thirteen thousand, five hundred and sixteen deliveries $(13,516)$, of which two hundred and sixty-three (263) were twin deliveries; giving the prevalence of twinning in RSUTH as 19.5 per 1000 deliveries or 1 in 51 deliveries.

Table 1 shows an increasing trend in the rate of twin pregnancy, from 7.6 per 1000 deliveries in 2015 to 35.7 per 1000 deliveries in 2019.

Table 2 shows the socio-demographic characteristics of the parturient. Their ages ranged from 19 to 49 years, with mean \pm SD $(31 \pm 4.82$ years $), 95 \%$ confidence interval $(95 \%$ CI: $30.42,31.59$ ). The modal age group was 30-34, accounting for $112(42.6 \%)$ cases of twin pregnancies followed by the age group 25-29 (26.6\%) (Table 2).

The parity of the parturient ranged from 0 to 7 , with modal parity being para 1 . Majority $(51.7 \%)$ of the parturient had secondary level education, while 101 (38.1\%) and 24 (9.15) had tertiary and primary level education respectively. Two hundred and eight $(98.1 \%)$ of the mothers were Christians.

One hundred and sixty-four $(62.4 \%)$ of the parturient had preterm delivery while $99(37.6 \%)$ had term delivery. The mean gestational age at delivery was 35.7 SD 2.9 weeks, $95 \%$ confidence interval, 35.3 to 36.0 (Table 2 ).

Table 1: Yearly trend in twin pregnancy.

\begin{tabular}{|llll|}
\hline Year & No. of twin births & Total no. of births & Rate per 1000 births \\
\hline $\mathbf{2 0 1 5}$ & 23 & 3020 & 7.6 \\
\hline $\mathbf{2 0 1 6}$ & 44 & 3495 & 12.6 \\
\hline $\mathbf{2 0 1 7}$ & 59 & 2747 & 21.5 \\
\hline $\mathbf{2 0 1 8}$ & 67 & 2294 & 29.2 \\
\hline $\mathbf{2 0 1 9}$ & 70 & 1960 & 35.7 \\
\hline Total & 263 & 13516 & 19.5 \\
\hline
\end{tabular}


Table 2: Sociodemographic characteristics of study participants.

\begin{tabular}{|c|c|c|}
\hline Variables & Number $(\mathrm{N}=\mathbf{2 6 3})$ & Percentage $(\%)$ \\
\hline \multicolumn{3}{|l|}{ Age (years) } \\
\hline$<20$ & 2 & 0.8 \\
\hline $20-24$ & 23 & 8.7 \\
\hline $25-29$ & 70 & 26.6 \\
\hline $30-34$ & 112 & 42.6 \\
\hline $35-39$ & 47 & 17.9 \\
\hline $40-44$ & 6 & 2.3 \\
\hline $45-49$ & 2 & 0.8 \\
\hline$>49$ & 1 & 0.3 \\
\hline Mean age & SD & $95 \% \mathrm{CI}$ \\
\hline 31 & 4.8 & $30.4,31.6$ \\
\hline \multicolumn{3}{|c|}{ Gestational age (weeks) } \\
\hline$<37$ & 164 & 62.4 \\
\hline$>37$ & 99 & 37.6 \\
\hline Mean gestational age & SD & $95 \% \mathrm{CI}$ \\
\hline 35.7 & 2.9 & $35.3,36.0$ \\
\hline \multicolumn{3}{|l|}{ Parity } \\
\hline 0 & 10 & 3.8 \\
\hline 1 & 89 & 33.8 \\
\hline 2 & 83 & 31.6 \\
\hline 3 & 46 & 17.6 \\
\hline 4 & 24 & 9.1 \\
\hline$\geq 5$ & 11 & 4.2 \\
\hline \multicolumn{3}{|l|}{ Educational status } \\
\hline Non-formal & 2 & 0.8 \\
\hline Primary & 24 & 9.1 \\
\hline Secondary & 136 & 51.7 \\
\hline Tertiary & 101 & 38.4 \\
\hline \multicolumn{3}{|l|}{ Religion } \\
\hline Christianity & 208 & 98.1 \\
\hline Islam & 5 & 1.9 \\
\hline
\end{tabular}

Two hundred and thirty-two $(88.2 \%)$ of the parturient booked for antenatal care in hospital while 31 (19.8\%) were unbooked cases that presented to the hospital for delivery (Figure 1).

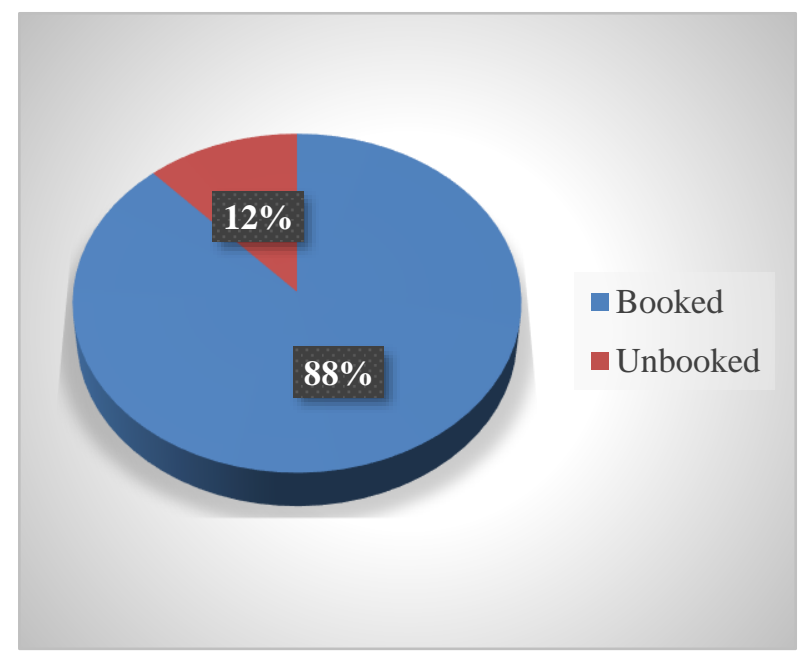

Figure 1: Booking status of the participants.
Figure 2 shows the modes of delivery. One hundred and seventy-seven $(67.3 \%)$ of the patients had caesarean section, and eighty-six vaginal delivery $(32.7 \%)$. Of the 177 patients that had caesarean section, $135(76.3 \%)$ had emergency caesarean section while $42(23.7 \%)$ elective caesarean section.

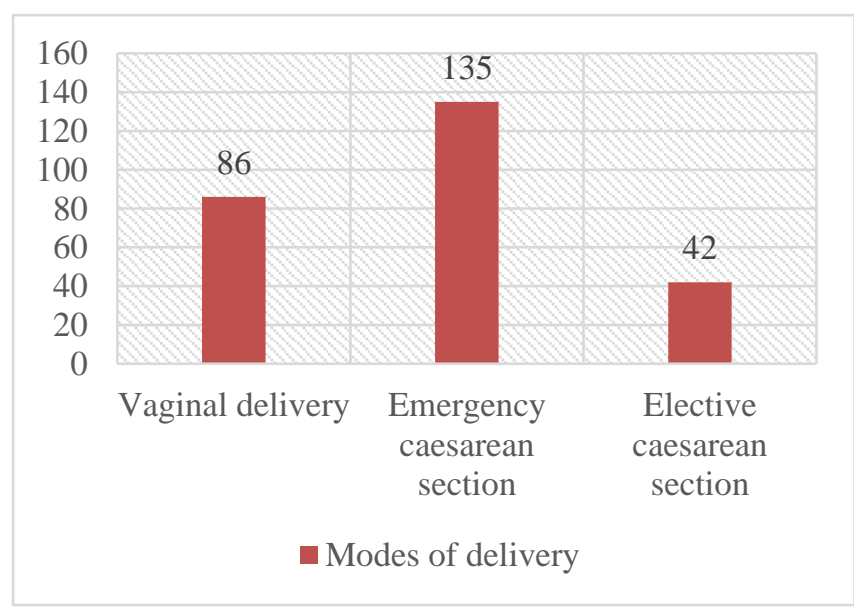

Figure 2: Modes of twin delivery. 
The mean birth weights of the first and second twins were 2.39 SD 0.67 and 2.30 SD 0.69 respectively. Figure 3 shows the distribution of the foetal birth weights. On hundred and forty-four, and one hundred and forty-two of twin 1 and twin 2 had birth weights greater than or equal to $2.5 \mathrm{~kg}$, while $91(34.6 \%)$ and $87(33.1 \%)$ of twin 1 and 2 had low birth weights respectively. Other categories of birth weights are as shown in Figure 3.
Of the 526 foetuses, $265(50.4 \%)$ were males and 261 (49.6\%) females, giving male to female ratio of 1.02:1 (Table 3).

Of the 526 foetuses, 485 babies were delivered alive, while 41 had still birth (Figure 4). The still birth rate and perinatal mortality rates were 4.2 and 7.8 per 1000 live births respectively (Table 4).

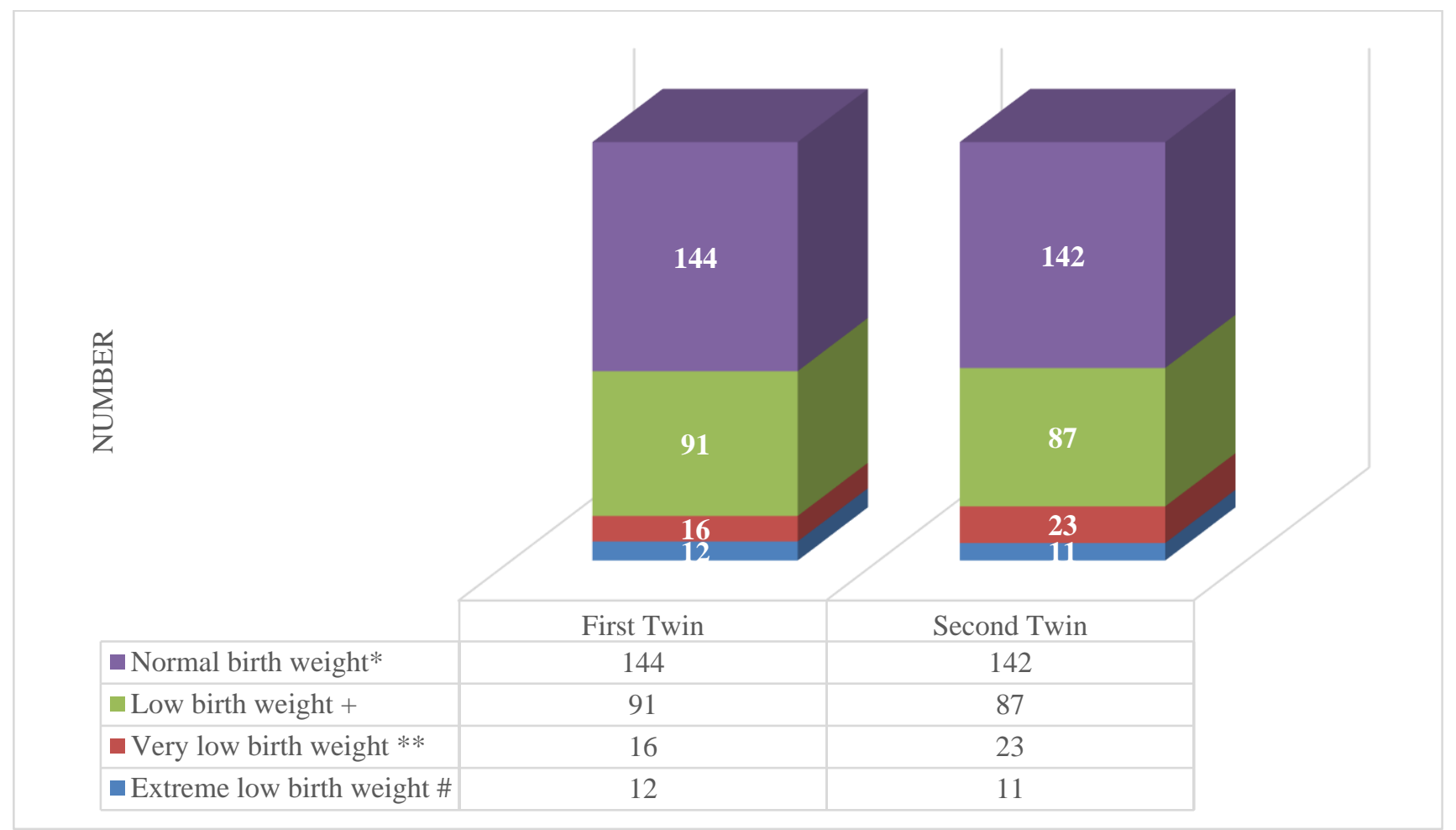

Note: $* 2.5-4 \mathrm{~kg},+1.5-2.49 \mathrm{~kg}, * * 1-1.49 \mathrm{~kg}, \#<1 \mathrm{~kg}$.

Figure 3: Categories of birth weight in twins.

Table 3: Sex distribution of the first and second twins.

\begin{tabular}{|lllll|}
\hline Twin & Foetal sex & & Total & Ratio (M/F) \\
\hline Twin 1 & Male (\%) & Female (\%) & 263 & $1.09: 1$ \\
\hline Twin 2 & $137(52.1)$ & $126(47.9)$ & 263 & $0.95: 1$ \\
\hline Total & $128(48.7)$ & $135(51.3)$ & 526 & $1.02: 1$ \\
\hline
\end{tabular}

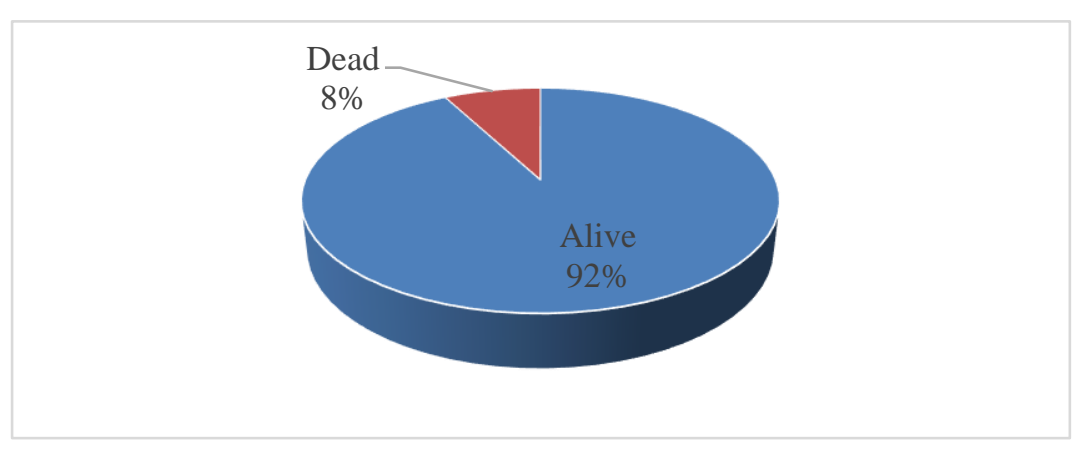

Figure 4: Foetal outcome at delivery. 
Table 4: Foetal mortality parameters.

\begin{tabular}{|l|c|}
\hline Variables & Number \\
\hline Still birth & 41 \\
\hline Early neonatal death & 35 \\
\hline Total Perinatal death & 76 \\
\hline Total number of live births & 9694 \\
\hline Still birth rate per 1000 live birth & 4.2 \\
\hline Perinatal mortality rate (PMR) per 1000 live births & 7.8 \\
\hline
\end{tabular}

\section{DISCUSSION}

The prevalence of twin pregnancy in RSUTH during the study period was 19.5 per 1000 deliveries or 1 in 51 deliveries. This finding is similar to the finding of 19 per 1000 deliveries in India, though the review in Uttarakhand, India, was for two years. ${ }^{1}$ Our finding is lower than reported values of 43/1000 in Ekiti, 35.2/1000 in Lagos South-West Nigeria, 32.5/1000 in Abuja North-Central, and $30.6 / 1000$ in Bayelsa, South-South Nigeria respectively.,12-14 However, our finding is higher than 16 per 1000 deliveries and 17.3 per 1000 deliveries reported in previous studies in South-South and North-East of Nigeria respectively, but comparable to 23.6/1000 reported in Edo, 22/1000 in Enugu and 23/1000 reported in Jos, Nigeria. ${ }^{9,15-18}$

Also, the finding from present study is higher than 14.1 and 17.7 per 1000 deliveries reported in Haiti and Egypt respectively. ${ }^{19}$ Although worldwide the rate of multiple pregnancy is highest in Nigeria, variations exist in the reported rates among different geopolitical and/or ethnic groups. This may be due to differences in methodology as well as the total number of deliveries. However, the highest incidence among the Yoruba ethnic group in South-West Nigeria has been attributed to consumption of yam rich in phytoestrogen..$^{20,21}$

Over the period reviewed, the trend of twin pregnancy increased from 7.6 per 1000 births in 2015 to 35.7 per 1000 births in 2019. This finding corroborates those of previous studies conducted in Nigeria. ${ }^{9,17}$ This increase may be attributed to availability of assisted reproductive services. ${ }^{10}$ Although, ART may not be cost effective to all that need the services in our poor economic setting, successes recorded over the years and availability of more private hospitals rendering such services could account for the increased rate.

The mean age of the patients was 31.0 SD 4.8 years, $95 \%$ CI: 30.4, 31.6 with modal age group 30-34 years. The age range (19-49 years) in present study indicates that the parturient were women of reproductive age. The study revealed an increasing rate of twinning with advancing maternal age. The proportion of women with twin gestation increased with advanced maternal age with modal age group being 30-34 years. This finding corroborates that of a recent study in Niger Delta region of
Nigeria. ${ }^{16}$ However, there was a marked decline among women aged 40-44 years and above. This may be due to higher chances of increased fertility in younger age group compared to older group. Advanced maternal age has also been shown to be associated with increased spontaneous dizygous twining especially those in the age group 30-39 years. $^{2}$

The mean gestational age at delivery was 35.7 SD 2.9 weeks, $95 \%$ confidence interval 35.3 to 36.0 . This finding is comparable to those of previous studies 35.5 weeks and 36.2, though lower than 36.6 and 36.9 weeks reported in Ekiti and Kano states of Nigeria respectively. ${ }^{11,12,16}$ However, the confidence interval presented in our study is helpful in interpretation of the finding. It shows that the true mean gestational age of the population lies between 35.3 and 36 weeks. Overall, this finding is in keeping with the report of increased preterm delivery associated with multiple pregnancy. ${ }^{4,7}$

Although the modal parity was para 1, more than half of twin pregnancies occurred in multiparous women compared to other parities. Studies have revealed that twinning occurs more in multiparous women. ${ }^{2,4}$ More than $97 \%$ of the parturient were Christians. This is not surprising because the predominant religion in the study location is Christianity.

In this study, majority of the patients booked for antenatal care. This is in agreement with the findings of previous studies. ${ }^{16,17}$ The high proportion of women in this study with formal education could account for this finding. Women with formal education, seems to have a higher chance of registering their pregnancies in a tertiary health facility for expert care compared to those without formal education. Additionally, the nature of multiple pregnancy as well as exaggerated pregnancy symptoms associated with it, could make pregnant women seek for care early in their pregnancy.

The rate of pre-term birth among women with twin gestation in present study is $62.4 \%$. This finding is in keeping with those of previous studies. ${ }^{17,18}$ This is not surprising because multiple pregnancy predisposes to preterm delivery perhaps due to overdistension of the uterus. Prematurity is a major complication of twin pregnancy, accounting for perinatal mortality in $10 \%$ and 
$50 \%$ of deliveries before 32 weeks and 37 weeks respectively. ${ }^{22}$

In this study, the commonest mode of delivery among women with twin gestation was caesarean section, accounting for $67.3 \%$. This is similar to findings of previous studies; but contrary to the finding of other studies in North-West and North-Central Nigeria, where most of the parturient had vaginal delivery. ${ }^{13,17,23-25}$ The high rate of caesarean section may be attributed to the unbooked cases referred to our centre for emergency caesarean section.

The mean birth weights of the first and second twins were 2.39 SD 0.67 and 2.30 SD 0.69 respectively. Although more than $50 \%$ of the foetuses had normal birthweight, one hundred and seventy eight of $526(33.8 \%)$ of the foetuses had low birth weight. This may be due to high proportion of preterm deliveries in this study, and in keeping with findings of previous studies. ${ }^{9,11}$

The still birth rate and perinatal mortality rate were 4.2 and 7.8 per 1000 live births respectively. This finding is lower than 207/1000 live births, 158.5/1000, reported in Uyo and Niger-Delta respectively. ${ }^{14,23}$ In the present study most of the mothers had antenatal care and elective delivery in the hospital. As such, early identification and prompt management of antenatal and intrapartum complications of twin pregnancies were instituted. This could have influenced the finding of reduced perinatal mortality observed in the study compared to other studies in the region.

\section{CONCLUSION}

The rate of twin pregnancy in our setting is high, and the trend over the years is on the increase. Majority of the mothers had preterm deliveries. Improved obstetric and neonatal care would reduce the morbidity and mortality associated with twin gestation.

\section{ACKNOWLEDGEMENTS}

Authors appreciate the staff of the Department of Obstetrics and Gynaecology, Rivers State University Teaching Hospital for their support during the study period.

Funding: No funding sources

Conflict of interest: None declared

Ethical approval: The study was approved by the Institutional Ethics Committee

\section{REFERENCES}

1. Upreti P. Twin pregnancies. Incidence and outcomes in a tertiary health centre of Uttarakhand, India. Int J Reprod Contracept Obstet Gynecol. 2018;7:3520-5.

2. Kilby MD, Oepkes D. Multiple pregnancy. In: Keith ED, Lees C, Bourne T, eds. Dewhurst's Textbook of
Obstetrics and Gynaecology. 9th ed. London: John Wiley and Sons Ltd; 2018: 281-293.

3. Wei J, Wu QJ, Zhang TN, Shen ZQ, Liu H, Zheng $\mathrm{DM}$, et al. Complications in multiple gestation pregnancy: a cross-sectional study of ten maternalfetal medicine centers in China. Oncotarget. 2016;7(21):30797.

4. Dimejesi IB, Agwu U, Emeka IEN. Multiple Pregnancy. In: Umeora OUJ, Onyebuchi AK, Ezeonu PO, eds. Our Teachers-A comprehensive Textbook of Obstetrics and Gynaecology. Abakaliki: St. Benedict Printing and Publishing; 2017: 159-164.

5. Nkyekyer K, Bonsafo K. Multiple pregnancy. In: Kwawukume EY, Ekele BA, Danso KA, Emuveyan EE, eds. Comprehensive Obstetrics in the Tropics. 2nd ed. Accara-North: Assemblies of God literature Centre Ltd; 2015: 207-216.

6. Santana DS, Silveira C, Costa ML, Souza RT, Surita FG, Souza JP, et al. Perinatal outcomes in twin pregnancies complicated by maternal morbidity: evidence from the WHO Multicountry Survey on Maternal and Newborn Health. BMC Pregnancy Childbirth. 2018;18(1):449.

7. Okunade KS, Daramola E, Adenekan M, Sekumade A, Ajepe A, Osanyin GE. Review of twin deliveries and fetomaternal outcomes in a Tertiary Hospital in Lagos, Southwest Nigeria. The Nigerian J General Practice. 2018;16(1):6.

8. Santana DS, Surita FG, Cecatti JG. Multiple Pregnancy: Epidemiology and Association with Maternal and Perinatal Morbidity. Rev Bras Ginecol Obstet. 2018;40(9):554-62.

9. Lawal AM, Atabo POD, Abdurrahman A. Twin pregnancies at federal medical centre Katsina: A 5 year review. Tropical J Obstet Gynaecol. 2019;36(2):183-8.

10. Wang AY, Safi N, Ali F, Lui K, Li Z, Umstad MP, Sullivan EA. Neonatal outcomes among twins following assisted reproductive technology: an Australian population-based retrospective cohort study. BMC Pregnancy Childbirth. 2018;18(1):1-7.

11. Attah RA, Mohammed Z, Gobir M. A review of twin deliveries in Aminu Kano Teaching Hospital, Northwest Nigeria. Nigerian J Basic Clinical Sci. 2014;11(1):3

12. Aduloju OP, Olofinbiyi B, Olagbuji BN, Ade OIP, Akintayo A. Obstetric outcome of twin gestations in a tertiary hospital South-western Nigeria. J MaternalFetal Neonatal Med. 2015;28(8):900-4.

13. Akaba GO, Agida TE, Onafowokan O, Offiong RA, Adewole ND. Review of twin pregnancies in a tertiary hospital in Abuja, Nigeria. J Health, Population, Nutrition. 2013;31(2):272.

14. Ibrahim I, Oyeyemi A, Obilahi A. Twin pregnancies in the Niger Delta of Nigeria. A four-year review. Int J Women's Health. 2012;4:245.

15. Bassey G, Inimgba NM. Fetomaternal outcome of twin gestation in Port Harcourt, South-South, Nigeria. Niger J Med. 2014;23(4):282-7. 
16. Maduabuchukwu IE, Howell IE. A Review of Twinning in Niger Delta Region, Nigeria. Clinical Med Res. 2018;7(1):18.

17. Nwankwo TO, Aniebue UU, Ezenkwele E, Nwafor MI. Pregnancy outcome and factors affecting vaginal delivery of twins at University of Nigeria Teaching Hospital, Enugu. Niger J Clin Pract. 2013;16(4):4905.

18. Mutihir JT, Aisien AO, Ujah IA. A review of bilateral tubal ligation at caesarean section in Jos, Nigeria. Niger Postgrad Med J. 2007;14(3):252-5.

19. Smits J, Monden C. Twinning across the Developing World. PLoS One. 2011;6(9):25239.

20. Iyiola O, Oyeyemi F, Raheem U, Mark F. Frequency of twinning in Kwara State, North-Central Nigeria. Egyptian J Med Human Genet. 2013;14(1):29-35.
21. Akinseye K, Anifowoshe A, Owolodun O, Aina O, Iyiola O. Frequency of Twinning in Nigeria. A Review. Manila J Sci. 2019;12:78-88.

22. Murray SR, Stock SJ, Cowan S, Cooper ES, Norman JE. Spontaneous preterm birth prevention in multiple pregnancy. Obstet Gynaecol. 2018;20(1):57.

23. Abasiattai AM, Umoiyoho AJ, Utuk NM, Shittu DG. Incidence and mode of delivery of twin pregnancies in Uyo, Nigeria. Nigerian Med J. 2010;51(4):170.

24. Akinboro A, Azeez M, Bakare A. Frequency of twinning in southwest Nigeria. Indian J Human Genet. 2008;14(2):41.

25. Yakasai IA, Rabiu A. Twins Birth in Kano, Northern Nigeria. IOSR J Pharm. 2013;20(3):1-5.

Cite this article as: Wekere FCC, John DH,

Clement-Wekere GAF, Iwo-Amah RS. Prevalence, trend and outcome of twin pregnancy in Rivers State University Teaching Hospital, Southern Nigeria. Int J Reprod Contracept Obstet Gynecol 2021;10:2571-7. 